\title{
Heterogeneously catalyzed lignin depolymerization
}

\author{
Antonio Pineda $^{1} \cdot$ Adam F. Lee $^{1}$
}

Received: 3 February 2016/Accepted: 24 May 2016/Published online: 3 June 2016

(c) The Author(s) 2016. This article is published with open access at Springerlink.com

\begin{abstract}
Biomass offers a unique resource for the sustainable production of bio-derived chemical and fuels as drop-in replacements for the current fossil fuel products. Lignin represents a major component of lignocellulosic biomass, but is particularly recalcitrant for valorization by existing chemical technologies due to its complex crosslinking polymeric network. Here, we highlight a range of catalytic approaches to lignin depolymerisation for the production of aromatic bio-oil and monomeric oxygenates.
\end{abstract}

Keywords Biomass $\cdot$ Lignin $\cdot$ Heterogeneous catalysis · Solid acid

\section{Introduction}

The concept of sustainability is now embedded throughout modern society, from the design of cities and methods of food production and transport, to the sourcing and recycling of natural resources. Integral to these developments are new technologies able to deliver chemicals and fuels from renewable, i.e., non-fossil, resources, of which biomass has emerged as one of the most abundant and economically attractive feedstocks. Lignocellulosic biomass, in particular, is considered an attractive source of biomass for low carbon energy thermal conversion technologies, such as pyrolysis and gasification, since its use, in this regard, faces only limited competition from the agricultural and paper sector. However, biomass as a replacement for

Adam F. Lee

a.f.lee@aston.ac.uk

1 European Bioenergy Research Institute, Aston University, Birmingham B4 7ET, UK fossil fuel feedstocks is problematic due to the high water and oxygen content of the former, the presence of a watersoluble fraction of alkaline and halogen elements, along with hazardous trace elements, and resultant low-energy density/heating value, $\mathrm{pH}$, and ash-fusion temperatures of biomass. The heterogeneous nature of biomass between different plants and microorganisms, and significant regional and seasonal variations even within the same species, further necessitate the development of versatile processes for the chemical transformation of biomass [1]. However, there are strong political and financial drivers for renewable energy technologies, with the European Union mandating that a $20 \%$ of overall energy consumption must derive from renewable sources by 2020 , rising to $27 \%$ by 2030. In regard of transportation fuels, $10 \%$ must originate from renewable resources, and provide reductions in greenhouse gas emissions of at least $35 \%$ as compared with fossil fuels (including emissions arising from cultivation, processing, and transport). Policy directives are also being introduced to ensure that land designated for biomass production for bio-fuels cannot have been previously used for carbon stock, such as wetlands or forest, or impact of regions with high biodiversity, such as primary forests or highly biodiverse grasslands [2].

Lignocellulosic biomass comprises lignin, cellulose, and hemicellulose, with lignin the second most abundant constituent after cellulose at around 10-30 wt\% (Fig. 1). Lignin is a highly branched phenolic polymer of high molecular weight, typically between 600 and $1500 \mathrm{kDa}$ [3], with an annual global production of around 40-50 million tons. It occurs primarily in plant cell walls, and the principal components are guaiacyl alcohol, syringyl alcohol, and p-coumaryl alcohol [4]. Lignin depolymerization can afford phenolic 'platform chemicals', and, consequently, has attracted a considerable attention for the 


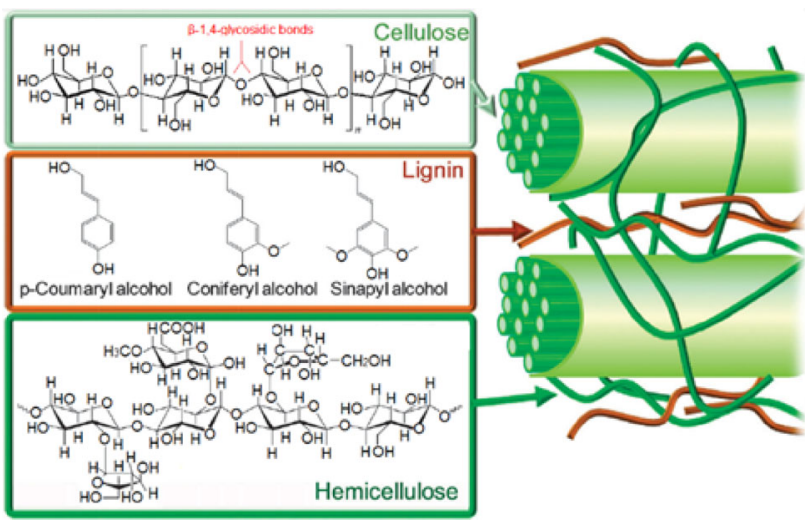

Fig. 1 Schematic of cellulose, hemicellulose, and lignin components of lignocellulosic biomass and associated molecular building blocks. Reproduced from Ref. [8] with permission of The Royal Society of Chemistry 2012

production of both chemicals and second generation biofuels (as a non-edible biomass feedstock). The selective cleavage of $\mathrm{C}-\mathrm{O}$ bonds that connect the monomers in lignin is a challenging, but offers compounds suitable for subsequent upgrading for fine chemicals applications, and has been achieved through solvolysis, hydrolysis, hydrogenolysis, pyrolysis, and alkaline oxidation. Oxidizing routes are generally undesirable due to radical formation which can result in partial repolymerization, whereas hydrogenolysis protocols minimize lignin repolymerization and promote $\mathrm{C}-\mathrm{O}$ bond cleavage by quenching and recombination of radicals, although the addition of molecular hydrogen can result in fully hydrogenated cyclic hydrocarbons of relatively low commercial value. Hydrogen-donating solvents able to generate/transfer hydrogen have, thus, also shown promise, e.g., Connors et al. report hydrogen transfer from ethanol, tetralin, and formic acid during lignin hydrocracking [5], while Kleinert et al. reported a novel solvolysis method employing high-pressure thermal treatment of lignin in the presence of ethanol as solvent and formic acid as hydrogen-donor, the latter decomposing to liberate $\mathrm{CO}_{2}$ and hydrogen [3]. Glycerol [6] and isopropanol [7] are also promising hydrogen-donor solvents. Due to the wide range of possible products, and strength of the $\mathrm{C}-\mathrm{O}$ bonds underpinning the lignin network, catalysts are essential to facilitate energy and atomefficient lignin depolymerization, and selectively deoxygenate the resulting products for fuel applications.

Lignin valorization is the key to fuels and chemicals coproduction from biomass through the biorefinery concept. Potential process under consideration within biorefineries fall into three broad classes, as categorized by Gallezot [9]: high-temperature thermal conversion via gasification or pyrolysis to deliver light gaseous or condensable molecules for subsequent transformation via established chemical processing, such as Fischer-Tropsch conversion of syngas; lower temperature catalytic or enzymatic conversion of lignin into aromatic building blocks, such as benzene, toluene, xylene, and phenol; or one-pot routes direct to highly functionalised products.

\section{The structure of lignin}

Lignin is a three-dimensional amorphous polymer whose most important building blocks are guaiacyl alcohol, syringyl alcohol, and p-coumaryl alcohol (Fig. 2a), linked predominantly by $\beta-\mathrm{O}-4$ bonds, in addition to $5-5, \alpha-\mathrm{O}-4$, $\beta-5,4-0-5, \beta-1$, dibenzodioxocin, and $\beta-\beta$ bonds. The structure and, hence, physicochemical properties of lignin vary with the biomass source, and hence the relative abundance of these monomeric sub-units. Hence, softwood lignin typically comprises $90 \%$ coniferyl alcohol, whereas similar amounts of coniferyl and sinapyl alcohol occur in hardwood lignins, with grass lignin a mix of coniferyl, sinapyl, and coumaryl alcohols $[10,11]$. Figure $2 b$ shows a lignin fragment and the estimated bond strengths of each ether linkage. The abundance of each bond type also varies with the lignin source, with around $39-48 \%$ of linkers $\beta$ O-4 bonds in softwood, but somewhat lower for hardwoods $(32-37 \%)[12,13]$. The heterogeneity of phenolic constituents and linkages is a significant barrier in the design lignocellulosic of biorefineries, since it prohibits a single protocol for lignin processing.

\section{Delignification of biomass}

Lignin isolation from lignocellulosic biomass is non-trivial due to competing condensation and oxidation reactions. Lignin is obtained commonly through either sulfur-derived technologies, such as those employing sulfites for Kraft lignins, or sulfur-free processes, in which lignin is extracted by organic solvents or alkaline solution. Additional methods employed to isolate lignin are indicated by the following nomenclatures: milled wood lignin, acidolysis lignin, cellulolytic enzyme lignin, enzymatic mild acidolysis lignin, pyrolysis lignin, and steam explosion lignin [15]. Alkaline lignin or Kraft lignin is produced in large quantities by the pulp and paper industry, which are, hence, the most abundant sources of lignin for the subsequent chemical processing [3]. In the Kraft process, lignocellulose is treated with either sodium hydroxide and/or sodium sulfide at $170{ }^{\circ} \mathrm{C}$, facilitating the separation of cellulosic fibers from lignin [16]; however, this approach is energy intensive, and the sulphite route introduces considerable sulfur into the resulting lignin. The Organosolv process for lignin isolation was developed by Theodor Kleinert [17], and as its name suggests employs organic solvents to 
Fig. 2 a Common building blocks of lignin and $\mathbf{b}$ exemplar polymer fragment of lignin and estimated bond strengths of ether linkers. Reproduced from Ref. [14] with permission of John Wiley \& Sons 2012

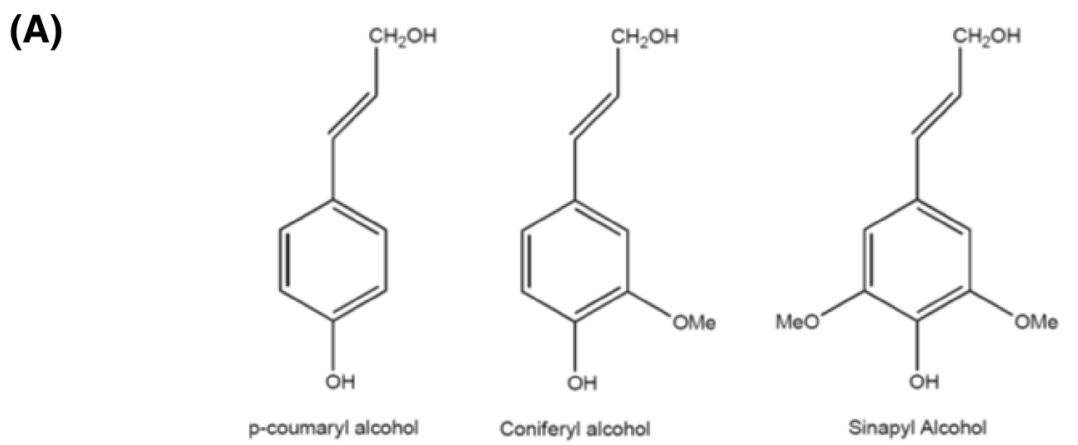

(B)

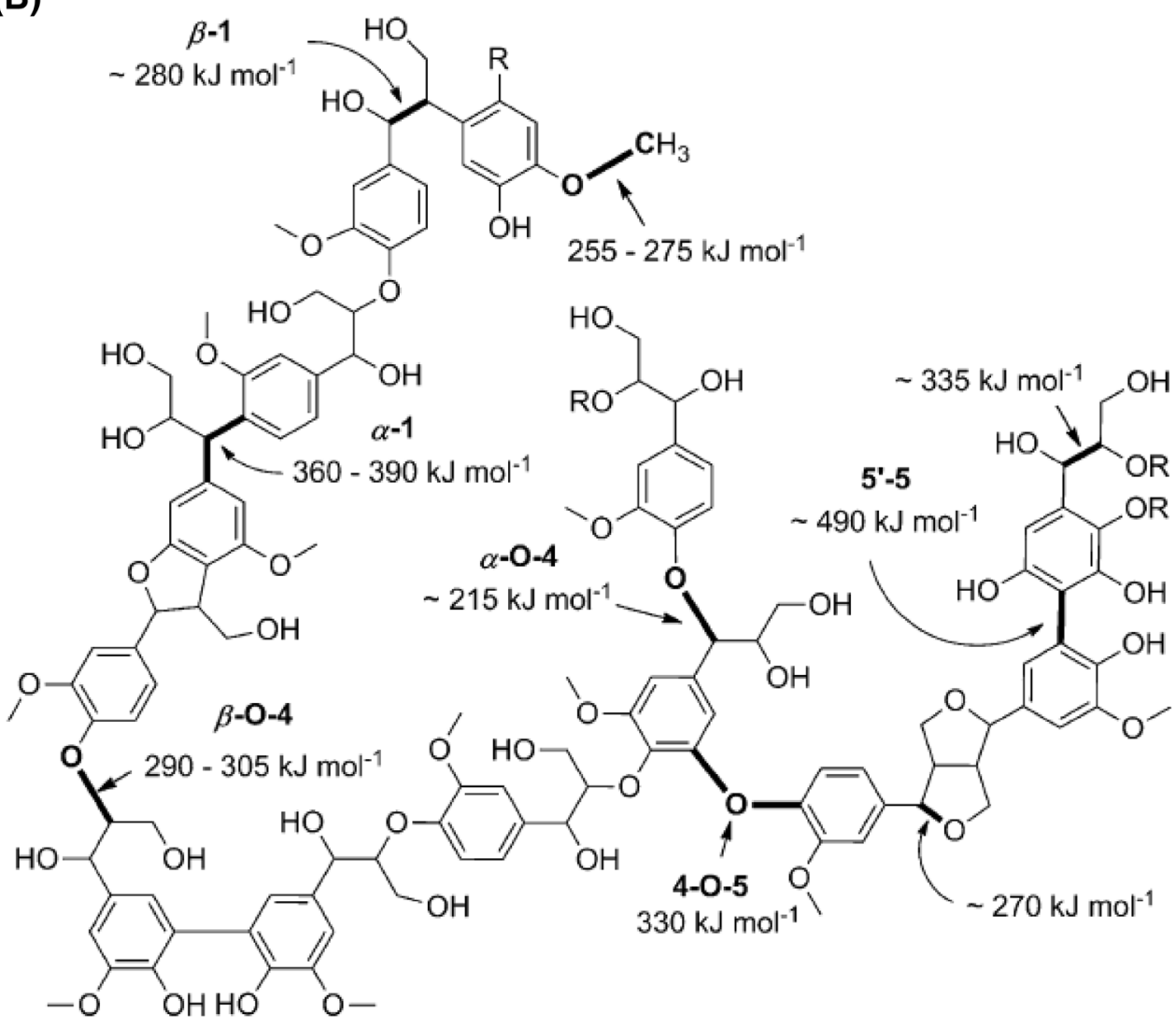

extract lignin, which consequently has a low ash and sulfur content compared with Kraft lignin. Depending on the severity of the treatment, partial dissolution of cellulose and hemicellulose may also occur [18]. The lignin extraction efficiency in an organic solvent, such as ethanol, can be increased by the addition of an inorganic acid, or by replacing ethanol with lower boiling point acetone which facilitates lignin recovery through simple distillation [18].

\section{Catalytic lignin depolymerization}

The decomposition of lignin into its constituent phenolic components is a hindered by the complex interconnectivity within the polymeric structure [19]. Diverse methods have been employed to produce phenolic compounds from lignin, including hydrolysis, hydrocracking (hydrogenolysis), and oxidation $[11,20]$. Oxidative cleavage of $\mathrm{C}-\mathrm{C}$ and $\mathrm{C}-$ $\mathrm{O}-\mathrm{C}$ bonds can afford vanillin and similar compounds accompanied by $\mathrm{CO}, \mathrm{CO}_{2}$, and $\mathrm{H}_{2} \mathrm{O}$ formation. However, oxidative protocols are undesirable, because the resulting free radicals drive recondensation. In contrast, reductive cleavage of such bonds has proven more successful for yielding monomeric compounds, such as phenols, benzene, toluene, and/or xylene.

Homogeneous catalysts have been rarely utilised due to their inherent disadvantages in respect of their difficult separation from the reaction mixture, corrosiveness (in the case of soluble acid catalysts), and, hence, are more favoured for selective bond cleavage within model 
compounds, but have been implemented in oxidative depolymerisation [21, 22]. The present review focuses on reductive catalytic solutions which favour phenolic compounds suitable for subsequent upgrading by HDO routes [23] to yield fuels and fuel additives.

\section{Hydrogenolysis}

Catalytic depolymerization is dominated by thermochemical transformations to monomeric phenols and typically requires harsh conditions due to the stability of the polyphenolic lignin structure. Organosolv lignin is more sensitive to hydrogenolysis due to its high degree of unsaturation and low molecular weight [24]. Bifunctional catalysts, containing both acid and noble metal sites, have attracted interest in this arena, since they can simultaneously cleave ether bonds and deoxygenate the resulting phenolic monomers in the presence of molecular $\mathrm{H}_{2}$ or a $\mathrm{H}$-donor solvent. The use of noble metal catalysts favours a mixture of cyclohexane derivatives and products arising from $\mathrm{C}-\mathrm{C}$ bond cleavage. Metallic nickel has shown the most promise for the production of phenolics from lignin due to its superior propensity for cleaving aryl-aryl $\mathrm{C}-\mathrm{O}-\mathrm{C}$ bonds and $\mathrm{C}-\mathrm{OH}$ bonds in side chains containing $\mathrm{CH}_{3}$ or $\mathrm{CH}_{2}$ functions, commonly yielding $\mathrm{C}_{1}-\mathrm{C}_{3}$ alkane-substituted guaiacols as the major product [25]. In the case of lignosulfates, $\mathrm{Ni}$ catalysts show good resistance to sulfur poisoning, while remaining active and selective for the transformation of lignosulfate into phenolics. While nickel is able to cleavage $\mathrm{C}-\mathrm{O}$ aliphatic bonds, it is less active for the rupture of aromatic $\mathrm{C}-\mathrm{O}$ and arene bonds. Lignin conversion to alkane-substituted guaiacols over $\mathrm{Ni}$ catalysts is independent of the support type (e.g., activated carbon, zeolite, or $\mathrm{MgO}$ ) [25]. Higher conversions were obtained in the presence of diol or triol functions, such us glycerol and ethylene glycol. Song and co-workers concluded that for lignosulfates, $\mathrm{Ni}(0)$ active sites catalyse hydrogenolysis of $\mathrm{C}-\mathrm{O}-\mathrm{C}$ bonds, $\mathrm{C}-\mathrm{OH}$ bonds in side alkyl chains, and the reduction of sulfonate groups into hydrogen sulfide $\left(\mathrm{H}_{2} \mathrm{~S}\right)$ [25].

He et al. [26] studied the cleavage of aromatic ether linkages by a nickel catalyst in model lignin compounds, such as benzyl phenyl ether, 2-phenylethyl phenyl ether, and diphenyl ether, which contain $\beta-\mathrm{O}-4, \alpha-\mathrm{O}-4$, and 4-O-5 bonds, respectively. These linkages could be selectively cleaved over $\mathrm{Ni} / \mathrm{SiO}_{2}$ to yield monomeric aromatic compounds, such as cycloalkanes and cyclohexanol, under moderate conditions $\left(120^{\circ} \mathrm{C}\right.$ and 6 bar $\mathrm{H}_{2}$ in aqueous medium). Two different mechanisms were proposed depending on the bond type, as illustrated in Fig. 2. Aromatic ethers containing $\beta-\mathrm{O}-4, \alpha-\mathrm{O}-4$ bonds underwent hydrogenolysis into monomeric units, while 4-O-5 bonds were broken by competing hydrolysis and hydrogenolysis pathways (see Fig. 3).

Supercritical solvents appear a favourable media for lignin depolymerization due to their advantageous properties in terms of hydrogen-donor capacity, rapid heat transfer, and high lignin solubility, with the product distribution strongly dependent on the catalyst/solvent combination. The formation of char by-products through repolymerization is reduced by the use of noble metal and nickel catalysts [27], in the presence of supercritical methanol, ethanol, and propanol, employing molecular $\mathrm{H}_{2}$ at $350{ }^{\circ} \mathrm{C}$. The highest lignin oil yield was obtained for a $\mathrm{Pt} / \mathrm{C}$ catalyst and ethanol solvent, and comprised monomeric phenols, including 4-ethylphenol, guaiacol, 4-ethylguaiacol, and syringol, along with heavier phenolic compounds. The combination of hydrogen in the gas phase and $\mathrm{H}$-donor solvents proved beneficial, favouring higher yields of monomeric phenols due to the quenching of free radicals and concomitant hampering of their recombination into oligomeric phenols [9]. Rinaldi et al. systematically investigated the effect of solvent choice on lignin conversion [14], finding that Lewis basic solvents, such as methanol and 1,4-dioxane, suppressed hydrogenation of aromatic products. In addition, lignin depolymerization was possible in solvents, in which it was insoluble due to the solubility of aromatic fragments formed in situ by lignin thermolysis around $250^{\circ} \mathrm{C}$, which subsequently underwent hydrogenolysis. However, lignin functionalities, such as alcohols lowered catalytic activity due to their preferential binding at catalyst active sites. The use of H-donor solvents without molecular hydrogen for the hydrogenolysis of lignin has also been explored by Toledano and co-workers over bifunctional $\mathrm{Ru}, \mathrm{Pt}, \mathrm{Pd}$, and $\mathrm{Ni}$ catalysts on a mesoporous aluminosilicate Al-SBA-15 support [28], prepared by ball-milling to maximize the accessibility of active sites which are predominantly located on the external surface [29]. Microwave irradiation was also utilised to lower the reaction temperature for catalytic lignin hydrogenolysis of lignin to $150{ }^{\circ} \mathrm{C}$. Nickel containing catalysts proved the most active, offering the highest conversion towards bio-oil (which mainly comprised phenolic monomers), as compared with noble metal catalysts, with the highest yield achieved for a $10 \mathrm{wt} \% \mathrm{Ni}$ catalyst and tetralin $\mathrm{H}$-donor solvent. The major monomeric phenols afforded by $\mathrm{Ni}$ catalysts under microwave irradiation were syringol, syringaldehyde, vanillin, and (des)aspidinol, with syringyl derivatives dominant. The higher activity of Ni catalyst was attributed to their larger particle size of $35-40 \mathrm{~nm}$ than of corresponding noble metals (around 5-6 $\mathrm{nm}$ ), which provided for increased interactions between the parent lignin and metal active sites; Ni catalysts also suppressed repolymerization. The performance of the optimum $10 \mathrm{wt} \% \mathrm{Ni} / \mathrm{Al}-\mathrm{SBA}-15$ 
Fig. 3 Proposed mechanism for $\mathrm{C}-\mathrm{O}$ cleavage in lignin model compounds over $\mathrm{Ni} / \mathrm{SiO}_{2}$ catalysts. Reproduced with permission from Ref. [26]. Copyright $(2012$ American Chemical Society

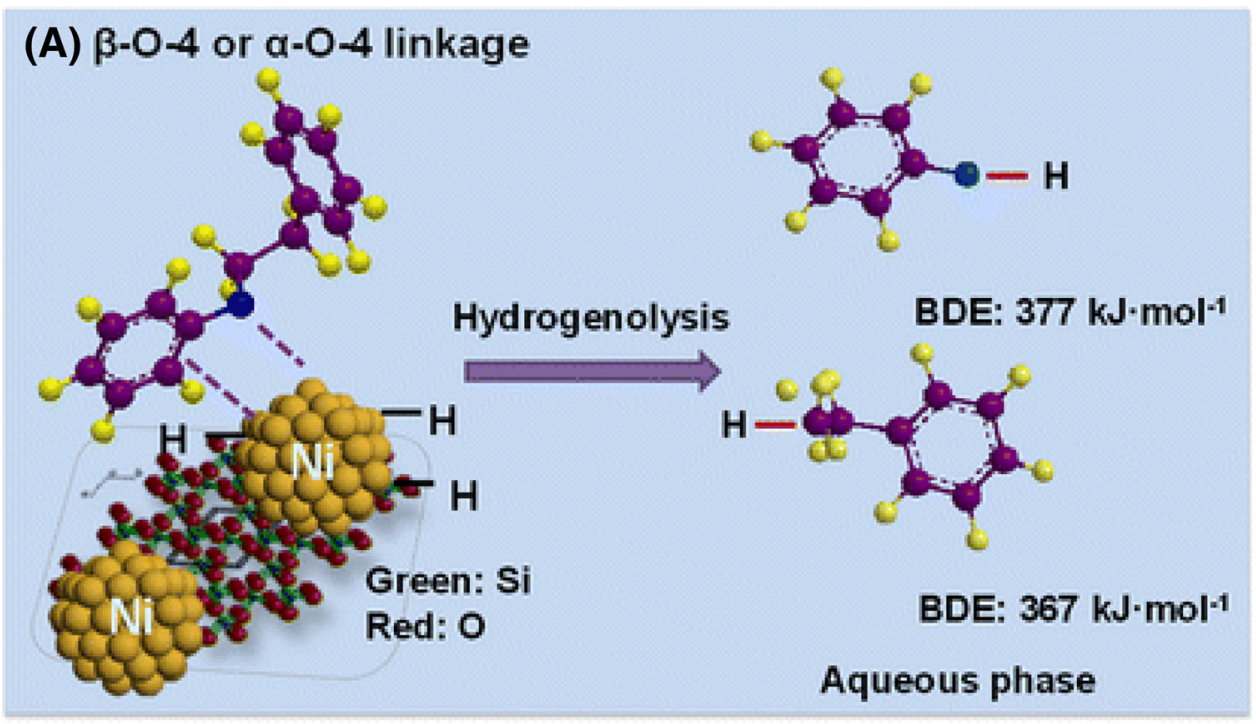

(B) 4-0-5 linkage

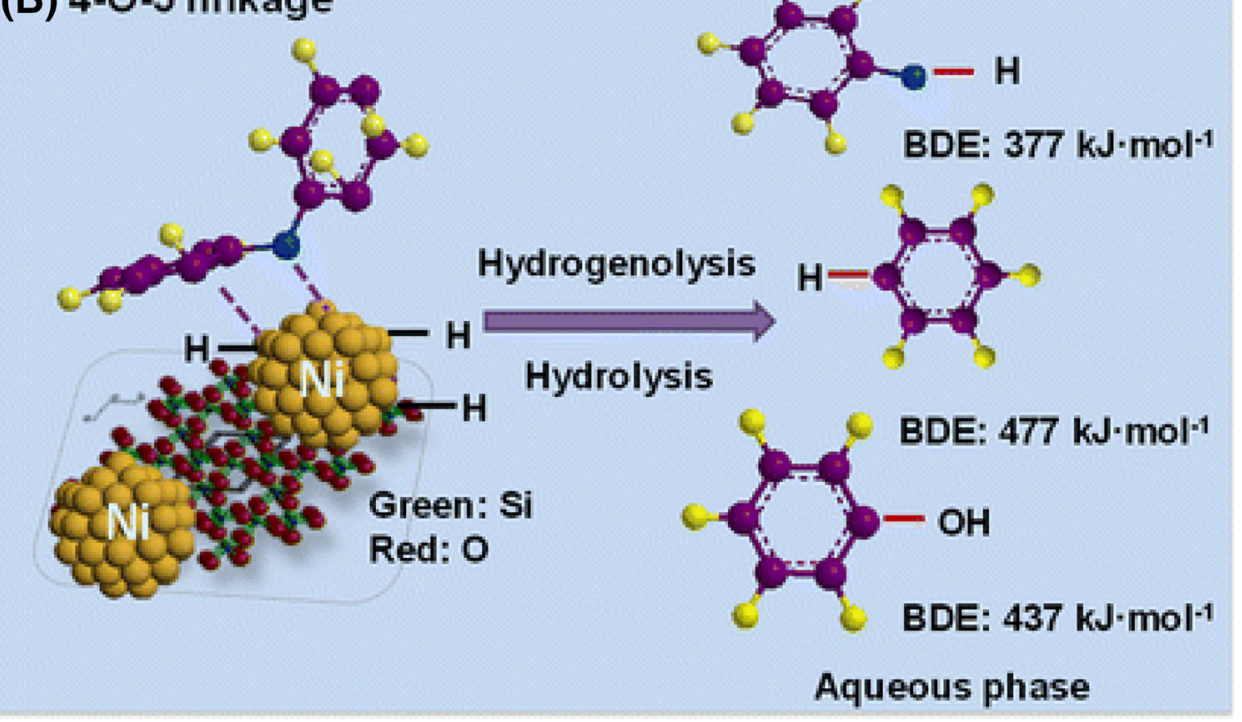

catalyst was then subject to a systematic study on the impact of H-donor solvent selection, including formic acid, tetralin, isopropanol, and lignin. Figure 4 shows the resulting distribution of products for each solvent. The yield of the desired bio-oil was high for formic acid, with minimal char formation and syringol as the major product (which was not observed when using isopropanol), the different product selectivities were attributed to differing rates of in situ hydrogen formation.

The combination of Raney Ni with an acidic zeolite also exhibited a synergetic effect in the depolymerization of a cellulolytic enzyme lignin using a methanol/water solvent mixture at $250{ }^{\circ} \mathrm{C}$ [31]. The monophenol yield increased from $12.9 \mathrm{wt} \%$ when the reaction was catalyzed by Raney $\mathrm{Ni}$ alone, to 21-27.9 wt\% when used in conjunction with an acid catalyst. Lignin depolymerization into aromatic monomers over solid acid catalysts, such as zeolites, clays, and sulphated zirconia, was evaluated by Deepa and Dhepe [32]. It was proposed that the improved yield from combining Raney Ni with a zeolite arose from the latter hindering the reaction between the parent lignin and other more reactive lignin fragments that could together to produce high molecular weight oligomers. Bimetallic NiM $(\mathrm{M}=\mathrm{Ru}, \mathrm{Rh}, \mathrm{Pd}, \mathrm{Au}, \mathrm{Mo})$ catalysts have also been studied for lignin hydrogenolysis [33, 34], [35] [36], wherein $\mathrm{NaOH}$ addition proved beneficial, promoting the formation of aromatic compounds and supressing arene hydrogenation. Konnerth et al. [37] also observed increased Organosolv lignin depolymerization via $\mathrm{NaOH}$ addition to the aqueous reaction mixture containing an $\mathrm{Ni}_{7} \mathrm{Au}_{3}$ 


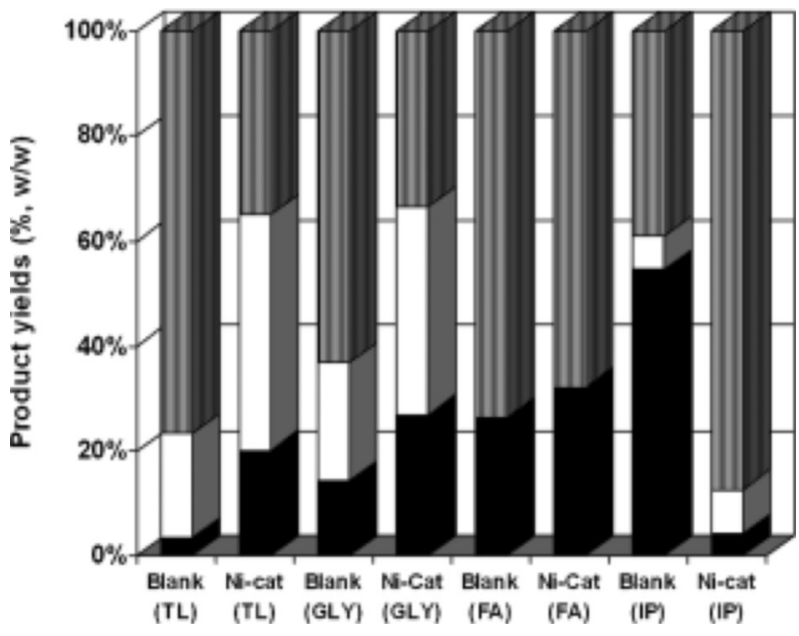

Fig. 4 Product yields for the catalytic hydrogenolysis of lignin over $\mathrm{Ni}$ catalysts in different hydrogen-donor solvents ( $T L$ tetralin, $G L Y$ glycerol, FA formic acid, and IP isopropanol; black square bio-oil, white square biochar, grey square residual lignin). Reproduced from Ref. [30] with permission of John Wiley \& Sons 2013

nanoparticle catalyst. It was speculated that the basic conditions favoured the formation of phenolate products, whose superior solvation inhibited their subsequent absorption and hydrogenation.

Molybdenum catalysts have also been studied for lignin depolymerization over different supports, including alumina and carbon [38, 39]. Ma et al. reported lignin depolymerization in supercritical ethanol over $\mathrm{Mo} / \mathrm{Al}_{2} \mathrm{O}_{3}$ and the optimum reduction temperature evaluated and identified as $750{ }^{\circ} \mathrm{C}$. Lignin was converted into a complex mixture of low molecular weight compounds, such as aliphatic alcohols, $\mathrm{C}_{8}-\mathrm{C}_{10}$ esters, monophenols, benzyl alcohols, and arenes [39]. The same authors reported that nanostructured $\mathrm{Mo}_{\mathrm{x}} \mathrm{C}$ achieved complete catalytic ethanolysis of Kraft lignin in supercritical ethanol under $\mathrm{N}_{2}$ at $280{ }^{\circ} \mathrm{C}$ [38]. Hydrogen pressure exerted a moderate influence on the yield of liquid products, increasing alcohol production at the expense of esters. The principal products were aliphatics $\left(\mathrm{C}_{6}\right.$ alcohols and $\mathrm{C}_{8}-\mathrm{C}_{10}$ esters), and aromatics, including phenols, phenyl alcohols, and $\mathrm{C}_{8}-\mathrm{C}_{10}$ arenes, with negligible dimers, oligomers or char observed. Ethanol provided superior a liquid product yield to water, methanol, or isopropanol, with a complex interplay between the solvent, lignin source and reaction conditions. The small molecules produced through this route are amenable to the direct introduction to a petroleum refinery without further upgrading.

The role of each component within a $\mathrm{Cu}-\mathrm{Al}-\mathrm{Mg}$ mixed oxide catalyst for lignin depolymerization was investigated by Jensen et al. [40]. Here, ethanol participated as both solvent and an alkylation agent, reacting with higher alcohols, esters, aldehydes, ethers, and other small hydrocarbons, as shown in Fig. 5. The conversion of lignin into monomers is increased by the combination of $\mathrm{Cu}$ with and Lewis acid sites, when is supported over alumina, that increase the amount of monomers and quench the repolymerization. The combination of $\mathrm{Cu}$ with basic sites prompts ethanol dehydrogenation producing in the $\mathrm{H}_{2}$ necessary for hydrogenolysis and hydrodeoxygenation. In addition, the formation of char is reduced through Guebert reaction and esterification reactions, as it can be observed in scheme. The optimum composition found for the catalyst was a $20 \mathrm{wt} \%$ of $\mathrm{Cu}$ originated from a hydrotalcite with $(\mathrm{Cu}+\mathrm{Mg}) / \mathrm{Al}$ ratio of 4 gave the highest monomers yield and the char formation by repolymerization degree was lower.

Char formation during lignin depolymerization is highly undesirable. Cu-doped porous catalysts in supercritical methanol reportedly suppress chars, with hydrogen obtained by in situ solvent reforming [41]. A similar approach was adopted by Anastas et al. [42], employing porous metal oxides containing $\mathrm{Cu}^{2+}, \mathrm{Mg}^{2+}$, and $\mathrm{Al}^{3+}$, achieving almost complete lignin conversion to catechols under mild conditions of $140-220{ }^{\circ} \mathrm{C}$. The role of $\mathrm{Cu}$ as a char inhibitor was attributed to enhanced hydrogenolysis, dehydration, and hydrogenation steps after cleavage of $\beta$ O-4 linkers, eliminating product aromaticity [41, 42].

Klamrassamee et al. incorporated $\mathrm{ZrO}_{2}$ in MCM-41 and SBA-15 via wet impregnation as supports for the depolymerization of Organosolv lignin using methanol or water as solvents [43]. Zirconia was selected due to it hydrothermal stability and acidity, with the supports chosen for their mesoporous textural properties. Organosolv lignin was depolymerized at $250{ }^{\circ} \mathrm{C}$ under an atmospheric pressure or hydrogen, with MCM-41 and SBA-15 supported zirconia offering superior conversion to other $\mathrm{ZrO}_{2}$ analogues, attributed to the higher acidity of the silica supports.

\section{Pyrolysis}

Lignin transformation into monomeric units, such as aromatic hydrocarbons, can also be achieved via catalytic pyrolysis, wherein the use of a catalyst affords more heavily deoxygenated and less acidic bio-oils than thermal pyrolysis, thus improving their stability and heating value. In catalytic biomass pyrolysis, the vapours generated in the pyrolysis process are passed through a catalyst bed with a view to promoting deoxygenation through, e.g., decarbonylation, decarboxylation, or dehydration reactions. Lignin requires higher temperatures and long residence times than for catalytic pyrolysis of cellulosic materials [44]. Since lignin is the most thermally stable of the lignocellulosic biomass components, reaction temperatures typically exceed those of $500-550{ }^{\circ} \mathrm{C}$ required for cellulose and hemicellulose [45]. The major products of lignin 


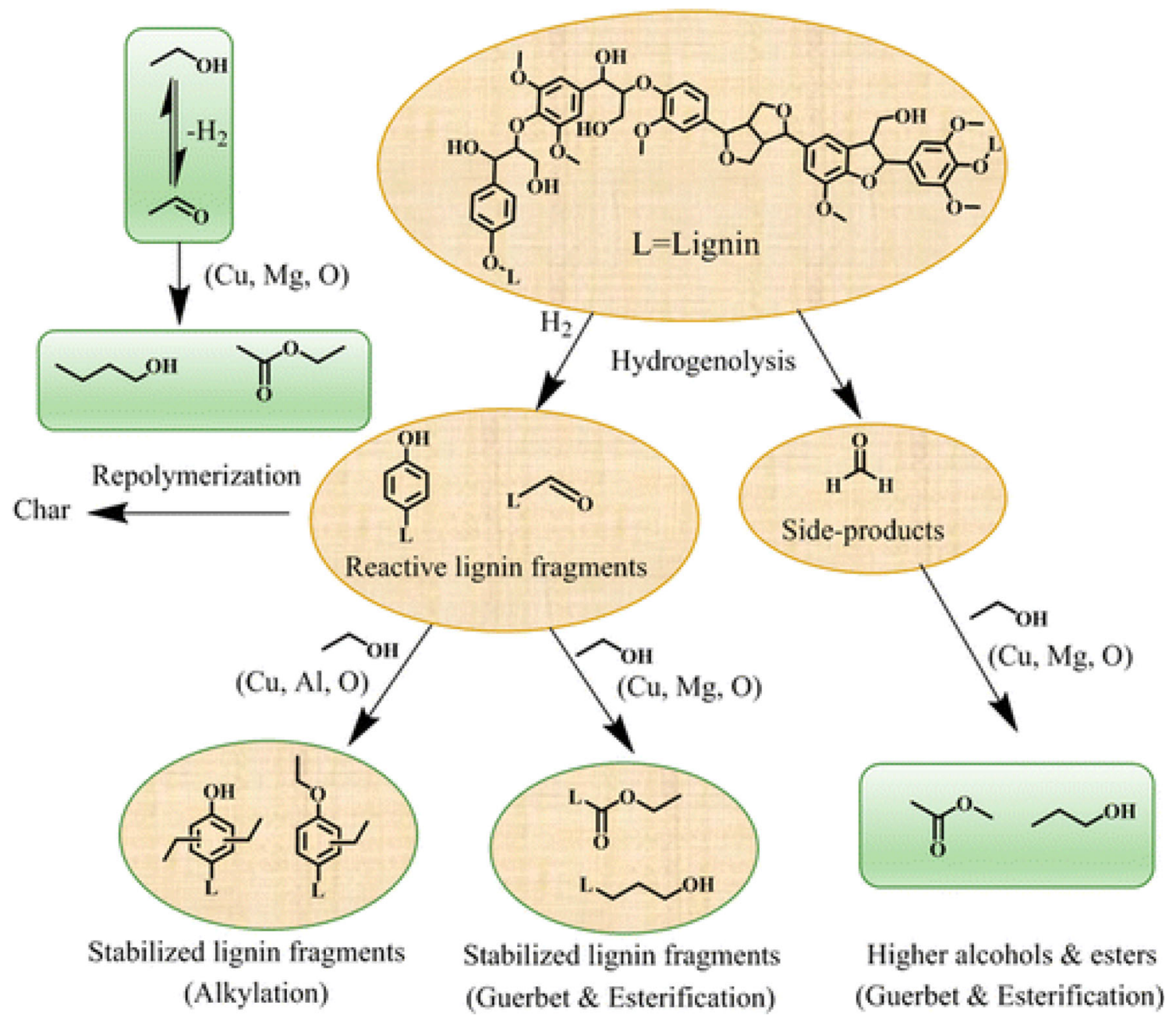

Fig. 5 Proposed reaction scheme for lignin depolymerization in ethanol over a $\mathrm{Cu}_{x} \mathrm{MgAl}_{y}$ catalyst. Reproduced from Ref. [40] with permission. Copyright (c) 2015 American Chemical Society

pyrolysis are phenolic compounds, such as phenol, guaiacol, and syringol [46-48].

The composition of bio-oils from lignin pyrolysis is influenced by the choice of catalyst and its physicochemical properties, notably the pore dimensions and nature of active sites. In the presence of zeolites, a low $\mathrm{Si} / \mathrm{Al}$ ratio and concomitant high density of acid sites yield high quantities of aromatic compounds. Larger pore sizes are able to accommodate bulkier molecules and deliver stable compounds, with Agrawal et al. [49] studying the influence of such parameters in the fast pyrolysis of alkaline lignin, achieving the highest yield of phenol alkoxyls for a ZSM-5 zeolite, while a USY zeolite favoured aromatic hydrocarbons possessing the highest number of acid sites of all zeolites examined (silicalite, Beta zeolite, and ZSM-5 zeolites with Si:Al ratios from 15 to 210). Brönsted acid sites within ZSM-5 zeolites are held responsible for cracking and reforming reactions [50], explaining the propensity for materials with low $\mathrm{Si}$ :Al ratios (high
Brönsted acid densities) to favour aromatic products $[45,49]$. The impact of zeolite pore size and coke formation has also been explored over ZSM-5, mordenite, Beta, and $\mathrm{Y}$ zeolites, which possess different pore architectures, but similar pore dimensions of between 5.6 and $7.6 \AA$ [49, 51]. Coking during lignin pyrolysis is considered a consequence of repolymerization reactions within zeolite pores. Zeolites must, thus, offer high activity towards lignin depolymerization into the desired compounds, while stabilising the products towards undesired coke formation (see Fig. 6).

A range of metal oxides $\left(\mathrm{Co}_{3} \mathrm{O}_{4}, \mathrm{MoO}_{3}, \mathrm{NiO}, \mathrm{Fe}_{2} \mathrm{O}_{3}\right.$, $\mathrm{MnO}_{3}$, and $\mathrm{CuO}$ ), mixed metal oxides, such as $\mathrm{CoO} / \mathrm{MoO}_{3}$, and supported metal oxides have also been explored for lignin pyrolysis $[48,53]$. In general, the liquid bio-oil yield was higher for all catalysts than for thermal pyrolysis, with phenol alkoxy compounds as the primary products over the metal oxides. Nickel and manganese oxide offered a similar product distribution to thermal pyrolysis, with 


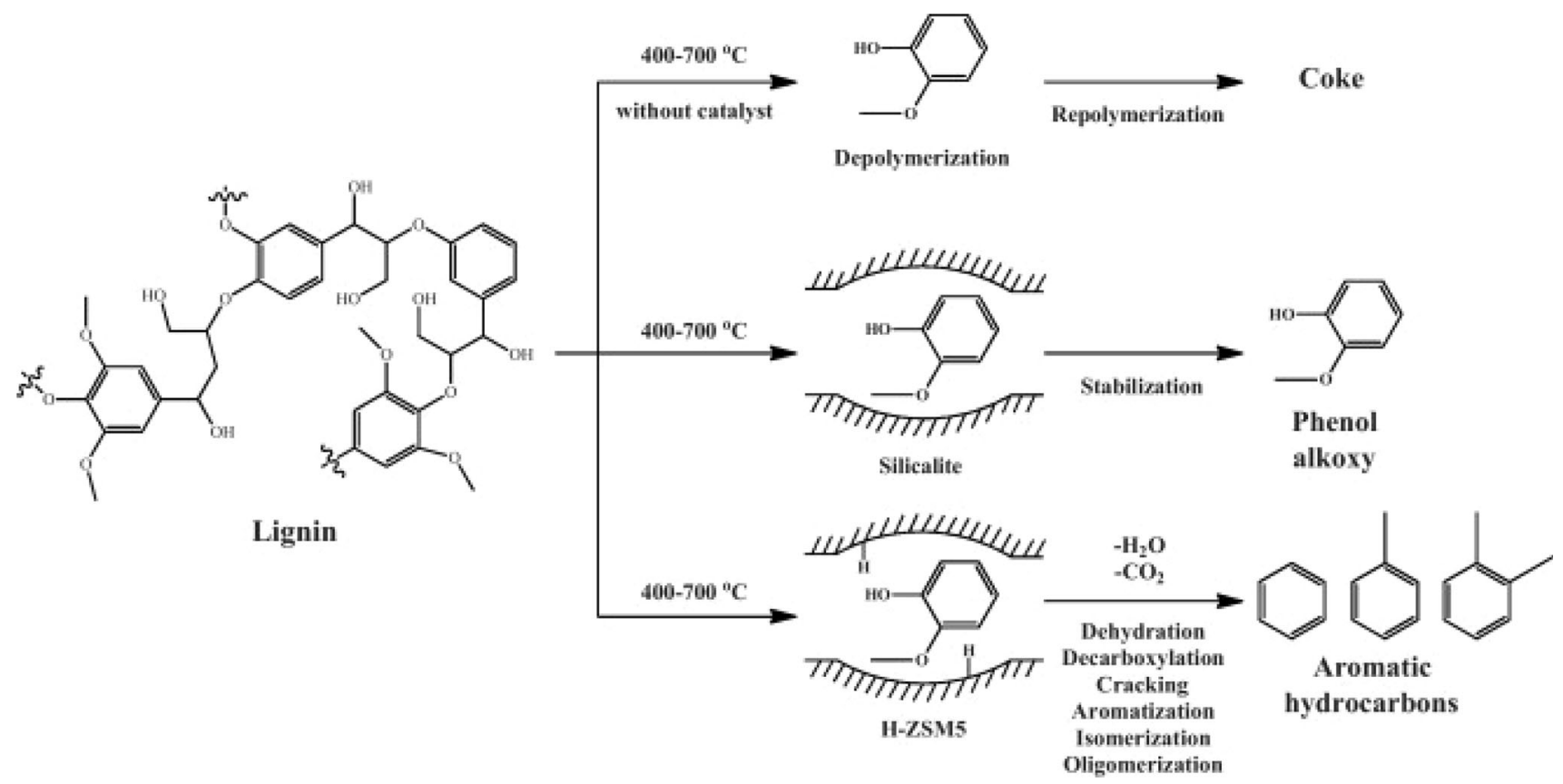

Fig. 6 Competing reaction pathways in thermal and catalytic fast pyrolysis of lignin over zeolites. Reproduced from Ref. [52] with permission from Elsevier

2-methoxy phenol favoured by $\mathrm{NiO}$ and $\mathrm{CuO}$, and $\mathrm{MoO}_{3}$ favouring vanillin instead of phenols and 2-methoxy phenols. The yield of aromatic hydrocarbons was increased by supporting nickel or cobalt oxides over ZSM-5 [53], which promoted direct deoxygenation of the aromatic lignin backbone compared to the unsupported metal oxide counterparts.

\section{Base-catalyzed depolymerization}

Lignin depolymerization over base catalysts is an excellent route to monomeric phenols. Aryl-alkyl ( $\beta-\mathrm{O}-4)$ ether bonds in lignin are easier to cleave than $\mathrm{C}-\mathrm{C}$ bonds in basecatalyzed lignin depolymerisation [54], although mineral bases typically require harsh reaction temperatures of around $340{ }^{\circ} \mathrm{C}$ [55-57], which can generate significant gaseous products via side reactions and consequent lower monomeric hydrocarbon yields [58]. In base-catalyzed depolymerization, the choice of lignin influences the yield of bio-oil, but not the resulting composition [59]; however, the use of mineral bases may necessitate neutralisation of the subsequent bio-oil, in addition to reactor corrosion. Thring et al. studied the effect of time and temperature on the depolymerization of Alcell lignin catalyzed by $\mathrm{NaOH}$ [57] obtaining guaiacol, syringol, and under certain conditions catechol and its derivatives [57, 60, 61]. Base-catalyzed depolymerization has proven an effective protocol in polar organic solvents, such as ethanol and methanol, suppressing char formation, and hence enhancing monomer and dimer production relative to solid acid catalysts. Toledano et al. [56, 62] reported that base catalysts prevent the repolymerization of monomeric products from lignin, offering improved bio-oil yields. Base strength plays an important role on the depolymerization mechanism, with hydroxides promoting phenol, cresol, guaiacol, catechol, and 4-methylcatecol production, while neither catechol or cresols were observed when using potassium carbonate [56]. The use of capping agents, such as boric acid, to protect hydroxyl groups in phenolic compounds has also been explored in efforts to minimize repolymerization, and results in lower molecular weight products [60]. In alkaline media, boric acid reacts with phenolic monomers to produce their respective esters $\left(\mathrm{NaB}(\mathrm{OR})_{4}\right)$, which hinders side reactions of phenol products and, in turn, hinders char formation. The formation of borated esters during basecatalyzed depolymerization also offers higher yields as compared with boric acid protection alone under analogous conditions [62]. The use of phenol was also explored as a capping agent to stabilise monomeric products of lignin depolymerization, with catechol and ferulic acid formed, whereas capping by boric acid yielded significant dimers. Toledano et al. [62] suggested that the different behaviour of these capping agents were due to boric acid trapping intermediates which lowered the yield of monomeric aromatics, whereas phenol capping reduced oligomerization, but not demethoxylation and dealkylation pathways.

$\mathrm{MgO}$ is a widely used solid base catalyst for biodiesel synthesis [63], and has also been employed for lignin 
depolymerisation in a range of solvents, including water, methanol, ethanol, and tetrahydrofuran (THF) [64]. Maximal lignin conversion was achieved for THF due to its superior solubilisation of lignin; however $\mathrm{MgO}$ also catalyzed repolymerization of phenol oligomers. Other solid bases, such as $\mathrm{RbCO}_{3} \mathrm{CsCO}_{3}$, have also shown promise for $\beta-\mathrm{O}-4$ cleavage of ether bonds in lignin model compounds, but are able to suppress char formation and increase bio-oil yield $[65,66]$.

Considering that lignin depolymerization can be performed successfully with homogeneous base catalysts, such as $\mathrm{KOH}$ and $\mathrm{NaOH}$, with conversions reaching $95 \%$ [55], [60], and that heterogeneous $\mathrm{Ni}$ catalysts are able to cleave C-O bonds [67], Sturgeon et al. proposed a combination of these active components [19]. A 5 wt $\% \mathrm{Ni}$ supported on a MgAl hydrotalcite (a solid base catalyst employed widely for lipid transesterification to biodiesel [68-70]) was shown to depolymerise a lignin model compound, 2-phenoxy-1-phenethanol, and ball-milled lignin extracted from corn stover, into low molecular weight alkyl aromatics; interestingly, nickel nanoparticles present on the (likely external) hydrotalcite surface required no activation with $\mathrm{H}_{2}$ prior to their catalytic application, suggesting that the active species was a mixed valence nickel oxide. Catalytic properties of nickel hydrotalcites are strongly influenced by the nature of interlayer anion. The presence of $\mathrm{NO}_{3}{ }^{-}$anions, or other basic anions, such as $\mathrm{OH}^{-}$and $\mathrm{CO}_{3}{ }^{2-}$, in the interlayers conferred up to a three-fold activity enhancement in the depolymerisation of the model lignin compound 2-phenoxy-1-phenethanol [71], wherein acetophenone (and phenol) were the principal products. Although the origin of this base promotion remains unclear, the depolymerisation mechanism may involve direct nitration of the phenolic. The same nitrate intercalated $\mathrm{Ni}$ hydrotalcite also proved effective for the depolymerization of enzymatically hydrolyzed lignin from corn stover, resulting in a large proportion of low molecular weight products, predominantly phenol, guaiacol, and syringol monomers, when performed in water, as compared with 4-vinylphenol when conducted in 3-methyl-3-pentanol at temperatures $<200{ }^{\circ} \mathrm{C}$.

\section{Oxidative transformations}

Oxidative depolymerization is often considered undesirable due to the propensity for generating free radicals which may promote repolymerization of the desired mono/ dimeric products and consequent char production. However, oxidative protocols can be advantageous, since they permit retention of both aromatic and acyclic organic frameworks without $\mathrm{C}-\mathrm{C}$ bond scission. Oxidative degradation is the route adopted for lignin decomposition in the natural world [72], and offers a hydrogen-free pathway to vanillin [11, 73]. A range of organometallics (notably methyl trioxo rhenium), polyoxometalates, and vanadium catalysts are reported for the oxidative depolymerization of lignin. Vanadium-oxo complexes have also been demonstrated as efficient catalysts for $\mathrm{C}-\mathrm{O}$ bond cleavage in lignin model compounds [74]. Silk et al. showed that the choice of vanadium complex strongly influenced selectivity, directing either the cleavage of $\mathrm{C}-\mathrm{C}$ bonds between an aryl ring and the contiguous group, or $\mathrm{C}-\mathrm{O}$ linkages scission [75]. Polyoxometalates are robust redox catalysts, and effective for oxidative degradation; when performed in the presence of molecular oxygen, a two-step process occurs, in which the polyoxoanion is first reduced and, subsequently, reoxidised without any net structural change [76]. Polyoxometalates applied for the decomposition of lignin residues under molecular oxygen often yields $\mathrm{CO}_{2}$ and $\mathrm{H}_{2} \mathrm{O}$ by-products [77]. Dimethyl succinate and aromatics have also been produced from pyrolytic lignin using a vanadium/molybdenum polyoxometalate in a methanol/ water solvent mixture under oxygen [72]. Bio-oil production increased with the amount of methanol (or ethanol) via methanol oxidation to $\mathrm{CCH}_{3}$ and $\mathrm{CH}_{3} \mathrm{OC}$ radicals which promoted lignin depolymerization. However, the addition of methanol (or ethanol) under alkaline conditions did not favour monomeric products [78]. The major products using a $\mathrm{H}_{5} \mathrm{PMo}_{10} \mathrm{~V}_{2} \mathrm{O}_{40}$ catalyst were organic acids and their esters, such as dimethyl fumarate and dimethyl succinate, formed by the breakdown of aromatics [79].

Salen complexes, particularly of cobalt, have also been tested for oxidative lignin transformation by $\mathrm{H}_{2} \mathrm{O}_{2}$ or molecular oxygen. Copper complexes, such as $\mathrm{Cu}$-bipy and $\mathrm{Cu}$-phen, can also catalyse the oxidative transformation of lignin model compounds, such as veratryl alcohol and 2,2biphenol. Oxidation activity was a function the of steric and electronic ligand effects [75]. Hydrogen peroxide is widely used in organic transformations and, generally, considered as a green oxidant with water as the sole byproduct [80]. The in situ production of reactive oxygen species from peroxy species by reaction with $\mathrm{Cu}$ or $\mathrm{Fe}$ is termed the Fenton reaction [81], and been utilised for the degradation of veratryl alcohol [82].

A chemoselective method for the aerobic oxidation of secondary benzylic alcohols, in the presence of unprotected primary alcohols (abundant in lignin), has also been developed by combining 4-acetamido-TEMPO (as a radical oxidant) together with $\mathrm{HNO}_{3}$ and $\mathrm{HCl}$ [83, 84]. This approach has been applied to wood pulp delignification, in which oxidation of the $\mathrm{C}_{\alpha}$ alcohol to a ketone favours the breakdown of $\beta-\mathrm{O}-4$ linkages. Wang et al. [85] also reported a bifunctional $\mathrm{Pd} / \mathrm{CeO}_{2}$ catalyst able to efficiently cleave $\beta$-O- 4 bonds in the presence of $\mathrm{C}_{\alpha}$-hydroxyl group, in which synergy between palladium activation of the oxidant and the redox properties of ceria facilitates $\beta-\mathrm{O}-4$ 
cleavage; Pd is widely used in heterogeneous catalysis for aerobic alcohol oxidation [86-90]. This bifunctional catalyst was able to transform a range of Organosolv lignin in ethanol under oxygen to vanillin, guaiacol, and 4-hydroxybenzaldehyde.

Oxidative cleavage of a dilignol model compound, erythro-1-(3,4-dimethoxyphenyl)-2-(2-methoxyphenoxy)1,3-propanediol, was investigated employing transition metal containing hydrotalcite, and $\mathrm{V}(\mathrm{acac})_{3}$ and $\mathrm{Cu}\left(\mathrm{NO}_{3}\right)_{2} \cdot 3 \mathrm{H}_{2} \mathrm{O}$ mixtures, with molecular oxygen as the oxidant [91]. Oxidative depolymerization of the dilignol model was influenced by the solvent selection, with negligible conversion observed in toluene, but good activity obtained in pyridine resulting in veratric acid as the major product. The same catalysts were subsequently applied to both Organosolv and Kraft lignin; however, their performance could not be readily extrapolated from dilignol model due to the complexity of practical lignin sources and presence of zeolite contaminants; harsher reaction conditions (extended reaction duration and higher oxygen pressure) were required to depolymerize Organosolv lignin, even at lower concentrations than used for the dilignol model, although both $\mathrm{Cu}-\mathrm{V}$ hydrotalcite and $\mathrm{V}(\mathrm{acac})_{3} /$ $\mathrm{Cu}\left(\mathrm{NO}_{3}\right)_{2} \cdot 3 \mathrm{H}_{2} \mathrm{O}$ successfully cleaved $\beta-\mathrm{O}-4$ linkages and resinol components yielding dimeric and trimeric products.

\section{Use of ionic liquids}

Ionic liquids (ILs) have attracted a great deal of interest in recent years as green solvents suitable for the solubilisation of lignocellulosic biomass, that are insoluble in other media $[92,93]$. After dissolution in an IL, biomass is amenable to acid hydrolysis [94], acylation [95], and acetylation [96]. Selection of the appropriate IL is key to control the product selectivity in oxidative depolymerization [97]. Lignin depolymerization has proven possible under mild conditions of only $110-150{ }^{\circ} \mathrm{C}$ through the use of an acidic IL, 1-H-3methylimidazolium, via hydrolysis of ether bonds [98]. The most widely used ILs are 1-ethyl-3-methylimidazolium (EMIM) and 1-butyl-3- methylimidazolium (BMIM) with anionic counterions, such as trifluoromethanesulfonate [CF $\mathrm{CF}_{3} \mathrm{SO}$ [99]. Bosmann et al. [97] evaluated the choice of IL in the oxidative depolymerization of lignin catalyzed by iron, copper, and manganese salts. Highest conversion was found for $\mathrm{Mn}\left(\mathrm{NO}_{3}\right)_{2}$ in [EMIM] $\left[\mathrm{CF}_{3} \mathrm{SO}\right]$ after 24-h reaction at $100{ }^{\circ} \mathrm{C}$ and 8.5 bar air, yielding 2,6-dimethoxy-1,4-benzoquinone (DMBQ), and either syringaldehyde or vanillic acid [97]. Cobalt salts favoured the oxidation of benzyl and other alcohol functionalities within lignin after its complete dissolution in an IL, such as 1-ethyl-3-methylimidazolium diethylphosphate [EMIM][DEP], without modifying phenolic functionalities or 5-5' $\beta-\mathrm{O}-4$ phenilcoumaran bonds, explaining the absence of monomeric products [100].
[EMIM][DEP], thus provide an efficient medium for lignin oxidative degradation.

\section{Enzymatic lignin depolymerization}

Oxidative lignin depolymerization has also been catalyzed by enzymes, such as peroxidases [101, 102] and laccase, which are lignolytic enzymes [15]. Laccase and peroxidase are useful enzymes due to their low substrate specificity (i.e., broad chemical applicability) and wide range of $\mathrm{pH}$ stability [103], contrasting the general perception that enzymes have limited applicability in chemical synthesis due to their high specificity and narrow $\mathrm{pH}$ dependence [104]. Oxidative lignin degradation employing the peroxidase Pleurotous ostreaus was shown at $30^{\circ} \mathrm{C}$, under molecular $\mathrm{O}_{2}$ in a pH 4 buffer solution, yielding 2,6dimethoxy-1,4-benzoquinone, benzoic acid, butyl phthalate, and bis(2-ethylhexyl) phthalate. The decomposition mechanism was proposed to initiate via a phenoxy radical, formed by the oxidation of a free phenolic group, which promoted $\mathrm{C}_{\alpha}-\mathrm{C}_{\beta}$, cleavage, the oxidation of $\mathrm{C}_{\alpha}$ carbons, and $\beta-\mathrm{O}-4$ linker scission [102]. Enzyme immobilization has also been attempted to improve product separation and catalyst recovery and reuse from water. Horseradish peroxidase (HRP) have been chemically immobilised on alumina using a layer-by-layer methodology and applied to the oxidative functionalization of Kraft lignin residue, and exhibited superior depolymerization to the free enzyme [105], attaining $90 \%$ lignin conversion versus $50 \%$ for the native enzyme. This enhancement was attributed to the enzyme stabilization provided by the electrolyte coating in the support employed during the immobilization process. In this case, depolymerization was believed to compete with oxidative coupling reactions which consumed residual insoluble lignin resulting in the formation of higher molecular weight polymers. The amount of carboxylate groups increased without any change in the aliphatic hydroxyl groups, indicating that side chains were not oxidised. Figure 7 shows a tentative scheme for enzymatic lignin oxidation proposed by Perazzini et al. [105]. A multi-enzyme heterogeneous catalyst was created through the immobilization of horseradish and laccase enzymes over alumina, and evidenced a synergy between the two enzymes [103]. The high concentration of aliphatic and phenolic functions present in lignin suggested a hydrolytic process as the responsible for its depolymerization.

\section{Conclusions}

Lignin represents an important renewable resource for the production of chemicals and bio-fuels, and hence, its valorisation will play an increasingly important role in the 


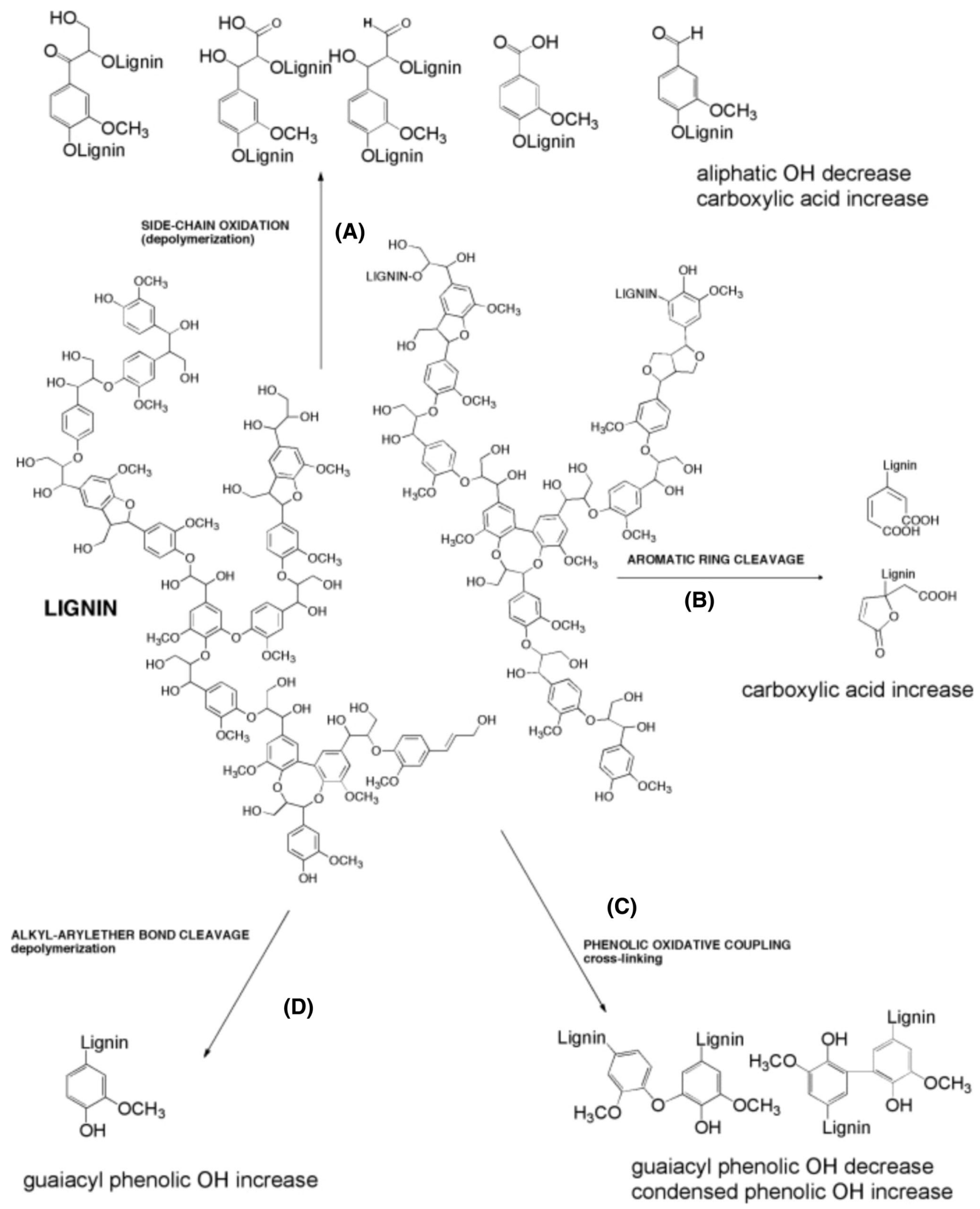

Fig. 7 Possible routes for the enzymatic oxidative depolymerisation of lignin. Reproduced from Ref. [105] with permission from Elsevier 
development of sustainable biorefineries. However, the heterogeneous nature of lignin presents significant obstacles for the establishment of a standard methodology for its depolymerization. The development of novel catalytic routes to lignin depolymerisation will facilitate more atom-efficient and energy-efficient processes, and safer approaches, such as the use of hydrogen-donor solvents instead of high-pressure molecular hydrogen. Heterogeneous catalysts will also afford facile catalyst separation/ reuse and product purification. Alternative solvents, such as ILs, are promising for low-temperature lignin decomposition in conjunction with the conventional mineral acids or tailored homogeneous/heterogeneous catalysts, although the high price and potential corrosiveness and toxicity of some ILs may limit their industrial scale application. The aromatic fraction produced through catalytic lignin depolymerization still exhibits a comparatively low heating value and high acid content, reflecting the high proportion of oxygenated compounds present in the bio-oil, and concomitant poor miscibility with aliphatic hydrocarbons, in addition to a broad boiling point range. Bio-oil upgrading technologies will, thus, be essential for either fuel or chemical applications; of these, hydrodeoxygenation (HDO) will likely prove most successful for biofuel, affording the complete hydrogenation of oxygenated depolymerisation products to benzene and cyclohexane.

Acknowledgments We thank the EPSRC (EP/K021796/1 and EP/ K029525/2) for financial support. Support from the European Union Seventh Framework Programme (FP7/2007-2013) under Grant Agreement No. 604307 is also acknowledged.

Open Access This article is distributed under the terms of the Creative Commons Attribution 4.0 International License (http:// creativecommons.org/licenses/by/4.0/), which permits unrestricted use, distribution, and reproduction in any medium, provided you give appropriate credit to the original author(s) and the source, provide a link to the Creative Commons license, and indicate if changes were made.

\section{References}

1. Vassilev SV, Vassileva CG, Vassilev VS (2015) Advantages and disadvantages of composition and properties of biomass in comparison with coal: an overview. Fuel 158:330-350

2. Directive 2009/28/EC of the European Parliament and of the Council of 23 April 2009 on the promotion of the use of energy from renewable sources and amending and subsequently repealing Directives 2001/77/EC and 2003/30/EC

3. Kleinert M, Barth T (2008) Phenols from lignin. Chem Eng Technol 31(5):736-745

4. White CA, Kennedy JF (1985) Recent advances in lignin biodegradation research edited by T. Higuchi, H.-M. Chang and T. K. Kirk, Uni Publishers Co., Japan, 1983. pp. xiv +279 , price \$30.00. Br Polym J 17(1):90
5. Connors WJ et al (1980) Thermal degradation of kraft lignin in tetralin. Holzforschung Int J Biol Chem Phys Technol Wood 34:29-37

6. Wolfson A et al (2009) Glycerol as solvent and hydrogen donor in transfer hydrogenation-dehydrogenation reactions. Tetrahedron Lett 50(43):5951-5953

7. Johnstone RAW, Wilby AH, Entwistle ID (1985) Heterogeneous catalytic transfer hydrogenation and its relation to other methods for reduction of organic compounds. Chem Rev 85(2):129-170

8. Alonso DM, Wettstein SG, Dumesic JA (2012) Bimetallic catalysts for upgrading of biomass to fuels and chemicals. Chem Soc Rev 41(24):8075-8098

9. Kim KH et al (2014) Hydrogen-donor-assisted solvent liquefaction of lignin to short-chain alkylphenols using a micro reactor/gas chromatography system. Energy Fuels 28(10):64296437

10. Evans RJ, Milne TA, Soltys MN (1986) Direct mass-spectrometric studies of the pyrolysis of carbonaceous fuels: III. Primary pyrolysis of lignin. J Anal Appl Pyrol 9(3):207-236

11. Zakzeski $\mathbf{J}$ et al (2010) The catalytic valorization of lignin for the production of renewable chemicals. Chem Rev 110(6):35523599

12. Parthasarathi R et al (2011) Theoretical study of the remarkably diverse linkages in lignin. J Phys Chem Lett 2(20):2660-2666

13. Younker JM, Beste A, Buchanan AC (2011) Computational study of bond dissociation enthalpies for substituted $\beta-O-4$ lignin model compounds. ChemPhysChem 12(18):3556-3565

14. Wang X, Rinaldi R (2012) Solvent effects on the hydrogenolysis of diphenyl ether with raney nickel and their implications for the conversion of lignin. ChemSusChem 5(8):1455-1466

15. Lange H, Decina S, Crestini C (2013) Oxidative upgrade of lignin-recent routes reviewed. Eur Polym J 49(6):1151-1173

16. Chakar FS, Ragauskas AJ (2004) Review of current and future softwood kraft lignin process chemistry. Ind Crops Prod 20(2):131-141

17. Kleinert N (1971) Organosolv pulping and recovery process. Patent US3585104

18. de la Torre MJ et al (2013) Organosolv lignin for biofuel. Ind Crops Prod 45:58-63

19. Sturgeon MR et al (2014) Lignin depolymerisation by nickel supported layered-double hydroxide catalysts. Green Chem 16(2):824-835

20. Pandey MP, Kim CS (2011) Lignin depolymerization and conversion: a review of thermochemical methods. Chem Eng Technol 34(1):29-41

21. Ma R, Xu Y, Zhang X (2015) Catalytic oxidation of biorefinery lignin to value-added chemicals to support sustainable biofuel production. ChemSusChem 8(1):24-51

22. Behling R, Valange S, Chatel G (2016) Heterogeneous catalytic oxidation for lignin valorization into valuable chemicals: what results? What limitations? What trends? Green Chem 18(7):1839-1854

23. Saidi $M$ et al (2014) Upgrading of lignin-derived bio-oils by catalytic hydrodeoxygenation. Energy Environ Sci 7(1):103-129

24. Shu $\mathrm{R}$ et al (2016) Investigation on the structural effect of lignin during the hydrogenolysis process. Bioresour Technol 200:14-22

25. Song Q, Wang F, Xu J (2012) Hydrogenolysis of lignosulfonate into phenols over heterogeneous nickel catalysts. Chem Commun 48(56):7019-7021

26. He JY, Zhao C, Lercher JA (2012) Ni-catalyzed cleavage of aryl ethers in the aqueous phase. J Am Chem Soc 134(51):2076820775

27. Kim J-Y et al (2015) Conversion of lignin to phenol-rich oil fraction under supercritical alcohols in the presence of metal catalysts. Energy Fuels 29(8):5154-5163 
28. Toledano A et al (2014) Microwave-assisted depolymerisation of organosolv lignin via mild hydrogen-free hydrogenolysis: catalyst screening. Appl Catal B 145:43-55

29. Pineda A et al (2011) A dry milling approach for the synthesis of highly active nanoparticles supported on porous materials. ChemSusChem 4(11):1561-1565

30. Toledano A et al (2013) Heterogeneously catalysed mild hydrogenolytic depolymerisation of lignin under microwave irradiation with hydrogen-donating solvents. ChemCatChem 5(4):977-985

31. Jiang Y et al (2015) Depolymerization of cellulolytic enzyme lignin for the production of monomeric phenols over raney ni and acidic zeolite catalysts. Energy Fuels 29(3):1662-1668

32. Deepa AK, Dhepe PL (2014) Solid acid catalyzed depolymerization of lignin into value added aromatic monomers. RSC Adv 4(25): $12625-12629$

33. Zhang JG et al (2014) A series of NiM (M=Ru, Rh, and Pd) bimetallic catalysts for effective lignin hydrogenolysis in water. Acs Catalysis 4(5):1574-1583

34. Zhang JG et al (2014) Highly efficient, NiAu-catalyzed hydrogenolysis of lignin into phenolic chemicals. Green Chem 16(5):2432-2437

35. Grilc M, Likozar B, Levec J (2014) Hydrodeoxygenation and hydrocracking of solvolysed lignocellulosic biomass by oxide, reduced and sulphide form of $\mathrm{NiMo}, \mathrm{Ni}$, Mo and Pd catalysts. Appl Catal B 150-151:275-287

36. Horacek $\mathbf{J}$ et al (2012) Lignin to liquids over sulfided catalysts. Catal Today 179(1):191-198

37. Konnerth $\mathrm{H}$ et al (2015) Base promoted hydrogenolysis of lignin model compounds and organosolv lignin over metal catalysts in water. Chem Eng Sci 123:155-163

38. Ma R et al (2014) Catalytic ethanolysis of kraft lignin into highvalue small-molecular chemicals over a nanostructured alphamolybdenum carbide catalyst. Angew Chem Int Ed 53(28):7310-7315

39. Ma X et al (2015) Alumina supported molybdenum catalyst for lignin valorization: effect of reduction temperature. Bioresour Technol 192:17-22

40. Huang $\mathrm{X}$ et al (2015) Role of $\mathrm{Cu}-\mathrm{Mg}-\mathrm{Al}$ mixed oxide catalysts in lignin depolymerization in supercritical ethanol. ACS Catal 5(12):7359-7370

41. Barta K et al (2010) Catalytic disassembly of an organosolv lignin via hydrogen transfer from supercritical methanol. Green Chem 12(9):1640-1647

42. Barta K et al (2014) Depolymerization of organosolv lignin to aromatic compounds over $\mathrm{Cu}$-doped porous metal oxides. Green Chem 16(1):191-196

43. Klamrassamee $\mathrm{T}$ et al (2015) Effects of mesostructured silica catalysts on the depolymerization of organosolv lignin fractionated from woody eucalyptus. Bioresour Technol 180:222-229

44. Nowakowski DJ et al (2010) Lignin fast pyrolysis: results from an international collaboration. J Anal Appl Pyrol 88(1):53-72

45. Li X et al (2012) Catalytic fast pyrolysis of Kraft lignin with HZSM-5 zeolite for producing aromatic hydrocarbons. Front Environ Sci Eng 6(3):295-303

46. Azeez AM et al (2011) Effects of zeolites on volatile products of beech wood using analytical pyrolysis. J Anal Appl Pyrol 91(2):296-302

47. Jackson MA, Compton DL, Boateng AA (2009) Screening heterogeneous catalysts for the pyrolysis of lignin. J Anal Appl Pyrol 85(1-2):226-230

48. Mullen CA, Boateng AA (2010) Catalytic pyrolysis-GC/MS of lignin from several sources. Fuel Process Technol 91(11):1446-1458
49. Agrawal S, Singh B, Sharma YC (2012) Exoskeleton of a mollusk (Pila globosa) as a heterogeneous catalyst for synthesis of biodiesel using used frying oil. Ind Eng Chem Res 51(37):11875-11880

50. Idem RO, Katikaneni SPR, Bakhshi NN (1997) Catalytic conversion of canola oil to fuels and chemicals: roles of catalyst acidity, basicity and shape selectivity on product distribution. Fuel Process Technol 51(1-2):101-125

51. Ma Z, van Bokhoven JA (2012) Deactivation and regeneration of H-USY zeolite during lignin catalytic fast pyrolysis. ChemCatChem 4(12):2036-2044

52. Ma Z, Troussard E, van Bokhoven JA (2012) Controlling the selectivity to chemicals from lignin via catalytic fast pyrolysis. Appl Catal A 423-424:130-136

53. Ma Z, Custodis V, van Bokhoven JA (2014) Selective deoxygenation of lignin during catalytic fast pyrolysis. Catal Sci Technol 4(3):766-772

54. Roberts V et al (2010) Influence of alkali carbonates on benzyl phenyl ether cleavage pathways in superheated water. Appl Catal B 95(1-2):71-77

55. Miller JE et al (1999) Batch microreactor studies of lignin and lignin model compound depolymerization by bases in alcohol solvents. Fuel 78(11):1363-1366

56. Toledano A, Serrano L, Labidi JJ (2012) Organosolv lignin depolymerization with different base catalysts. Chem Technol Biotechnol 87(11):1593

57. Thring RW (1994) Alkaline degradation of ALCELL ${ }^{\circledR}$ lignin. Biomass Bioenergy 7(1):125-130

58. Xu C et al (2014) Lignin depolymerisation strategies: towards valuable chemicals and fuels Chem. Soc Rev 43:7485

59. Erdocia X et al (2014) Base catalyzed depolymerization of lignin: influence of organosolv lignin nature. Biomass Bioenergy 66:379-386

60. Roberts VM et al (2011) Towards quantitative catalytic lignin depolymerization. Chem Eur J 17:5939

61. Chen HZ et al (2015) Depolymerization of renewable resourceslignin by sodium hydroxide as a catalyst and its applications to epoxy resin. J Appl Polym Sci 132(26): 10

62. Toledano A, Serrano L, Labidi J (2014) Improving base catalyzed lignin depolymerization by avoiding lignin repolymerization. Fuel 116:617

63. Montero JM et al (2009) Structure-sensitive biodiesel synthesis over $\mathrm{MgO}$ nanocrystals. Green Chem 11(2):265-268

64. Long $\mathrm{J}$ et al (2014) An efficient and economical process for lignin depolymerization in biomass-derived solvent tetrahydrofuran. Bioresour Technol 154:10-17

65. Dabral S et al (2015) Base-catalysed cleavage of lignin [small beta]-O-4 model compounds in dimethyl carbonate. Green Chem 17(11):4908-4912

66. Karagöz $\mathrm{S}$ et al (2004) Effect of $\mathrm{Rb}$ and Cs carbonates for production of phenols from liquefaction of wood biomass. Fuel 83(17-18):2293-2299

67. Sergeev AG, Webb JD, Hartwig JF (2012) A heterogeneous nickel catalyst for the hydrogenolysis of aryl ethers without arene hydrogenation. J Am Chem Soc 134(50):20226-20229

68. Woodford JJ et al (2012) Better by design: nanoengineered macroporous hydrotalcites for enhanced catalytic biodiesel production. Energy Environ Sci 5(3):6145-6150

69. Creasey JJ et al (2015) Facile route to conformal hydrotalcite coatings over complex architectures: a hierarchically ordered nanoporous base catalyst for FAME production. Green Chem 17(4):2398-2405

70. Creasey JJ et al (2014) Alkali- and nitrate-free synthesis of highly active Mg-Al hydrotalcite-coated alumina for FAME production. Catal Sci Technol 4(3):861-870 
71. Kruger JS et al (2016) Lignin depolymerization with nitrateintercalated hydrotalcite catalysts. ACS Catal 6(2):1316-1328

72. Zhao Y et al (2013) Depolymerization of lignin by catalytic oxidation with aqueous polyoxometalates. Appl Catal A 467:504-508

73. Ragauskas AJ et al (2014) Lignin valorization: improving lignin processing in the biorefinery. Science $34: 1246843$

74. Son S, Toste FD (2010) Non-oxidative vanadium-catalyzed c-o bond cleavage: application to degradation of lignin model compounds. Angew Chem 122(22):3879-3882

75. Korpi $\mathrm{H}$ et al (2006) Copper-2,2'-bipyridines: catalytic performance and structures in aqueous alkaline solutions. Appl Catal A 302(2):250-256

76. Ammam M (2013) Polyoxometalates: formation, structures, principal properties, main deposition methods and application in sensing. J Mater Chem A 1(21):6291-6312

77. Gaspar AR et al (2007) Alternatives for lignocellulosic pulp delignification using polyoxometalates and oxygen: a review. Green Chem 9(7):717-730

78. Voitl T, Rudolf von Rohr P (2008) Oxidation of lignin using aqueous polyoxometalates in the presence of alcohols. ChemSusChem 1(8-9):763-769

79. Kamwilaisak K, Wright PC (2012) Investigating laccase and titanium dioxide for lignin degradation. Energy Fuels 26(4):2400-2406

80. Noyori R, Aoki M, Sato K (2003) Green oxidation with aqueous hydrogen peroxide. Chem Commun 16:1977-1986

81. Wardman P, Candeias LP (1996) Fenton chemistry: an introduction. Radiat Res 145(5):523-531

82. Valenzuela R et al (2008) Copper catechol-driven Fenton reactions and their potential role in wood degradation. Int Biodeterior Biodegrad 61(4):345-350

83. Rahimi A et al (2014) Formic-acid-induced depolymerization of oxidized lignin to aromatics. Nature 515(7526):249-252

84. Rahimi A et al (2013) Chemoselective metal-free aerobic alcohol oxidation in lignin. J Am Chem Soc 135(17):6415-6418

85. Deng W et al (2015) Oxidative conversion of lignin and lignin model compounds catalyzed by $\mathrm{CeO}_{2}$-supported Pd nanoparticles. Green Chem 17(11):5009-5018

86. Guo Z et al (2014) Recent advances in heterogeneous selective oxidation catalysis for sustainable chemistry. Chem Soc Rev 43(10):3480-3524

87. Vinod CP, Wilson K, Lee AF (2011) Recent advances in the heterogeneously catalysed aerobic selective oxidation of alcohols. J Chem Technol Biotechnol 86(2):161-171

88. Hackett SFJ et al (2007) High-activity, single-site mesoporous $\mathrm{Pd} / \mathrm{A} 12 \mathrm{O} 3$ catalysts for selective aerobic oxidation of allylic alcohols. Angew Chem 119(45):8747-8750

89. Lee AF et al (2011) Reaction-driven surface restructuring and selectivity control in allylic alcohol catalytic aerobic oxidation over Pd. J Am Chem Soc 133(15):5724-5727
90. Lee AF (2013) Mechanistic studies of alcohol selective oxidation. In: Wilson K, Lee AF (eds) Heterogeneous catalysts for clean technology: spectroscopy, design, and monitoring. WileyVCH VerlagGmbH \& Co. KGaA, Weinheim, Germany, pp 11-38

91. Mottweiler J et al (2015) Copper- and vanadium-catalyzed oxidative cleavage of lignin using dioxygen. ChemSusChem 8(12):2106-2113

92. Lee SH et al (2009) Ionic liquid-mediated selective extraction of lignin from wood leading to enhanced enzymatic cellulose hydrolysis. Biotechnol Bioeng 102(5):1368-1376

93. Sheldon RA et al (2002) Biocatalysis in ionic liquids. Green Chem 4(2):147-151

94. Sievers C et al (2009) Ionic-liquid-phase hydrolysis of pine wood. Ind Eng Chem Res 48(3):1277-1286

95. Eta V, Mikkola J-P (2016) Deconstruction of Nordic hardwood in switchable ionic liquids and acylation of the dissolved cellulose. Carbohydr Polym 136:459-465

96. Ayoub A et al (2013) Development of an acetylation reaction of switchgrass hemicellulose in ionic liquid without catalyst. Ind Crops Prod 44:306-314

97. Stärk K et al (2010) Oxidative depolymerization of lignin in ionic liquids. ChemSusChem 3(6):719-723

98. Cox BJ, Ekerdt JG (2012) Depolymerization of oak wood lignin under mild conditions using the acidic ionic liquid 1-H-3methylimidazolium chloride as both solvent and catalyst. Bioresour Technol 118:584-588

99. Yinghuai Z, Yuanting KT, Hosmane NS (2013) Applications of ionic liquids in lignin chemistry. In: Kadokawa JI (ed) Ion Ionic Liquids - New Aspects for the Future, In Tech. doi:10.5772/ 51161

100. Zakzeski J, Jongerius AL, Weckhuysen BM (2010) Transition metal catalyzed oxidation of Alcell lignin, soda lignin, and lignin model compounds in ionic liquids. Green Chem 12(7):1225-1236

101. Ralph JP, Catcheside DEA (1998) Involvement of manganese peroxidase in the transformation of macromolecules from lowrank coal by Phanerochaete chrysosporium. Appl Microbiol Biotechnol 49(6):778-784

102. Shin KS, Lee YJ (1999) Depolymerisation of lignosulfonate by peroxidase of the white-rot basidiomycete, Pleurotus ostreatus. Biotechnol Lett 21(7):585-588

103. Crestini C, Melone F, Saladino R (2011) Novel multienzyme oxidative biocatalyst for lignin bioprocessing. Bioorg Med Chem 19(16):5071-5078

104. Berglund GI et al (2002) The catalytic pathway of horseradish peroxidase at high resolution. Nature 417(6887):463-468

105. Perazzini R et al (2011) A novel and efficient oxidative functionalization of lignin by layer-by-layer immobilised Horseradish peroxidase. Bioorg Med Chem 19(1):440-447 